\title{
HCA587/MAGE-C2 protein formulated with CFA and CpG elicits potent immune responses and antitumor effects in mice
}

\section{Wei Jiao}

the Second Affiliated Hospital of Nanchang University

Huiyuan Chen

the Second Affiliated Hospital of Nanchang University

Lijie Zhang

Shaanxi Provincial People's Hospital

Weiming Yang

the Second Affiliated Hospital of Nanchang University

Yanhui Yin

Peking University Health Science Center

Juanjuan Chen ( $\nabla$ ndefy11330@ncu.edu.cn )

the Second Affiliated Hospital of Nanchang University

\section{Research Article}

Keywords: HCA587 protein vaccine, CD4+ T cell, IFN- $y$, adjuvants, antitumor effect

Posted Date: March 8th, 2022

DOI: https://doi.org/10.21203/rs.3.rs-1320322/v1

License: () (1) This work is licensed under a Creative Commons Attribution 4.0 International License.

Read Full License 


\section{Abstract \\ Background}

HCA587/MAGE-C2 is a cancer-testis (CT) antigen, which is expressed in immunoprivileged germ-line regions and many kinds of tumor tissues. In the present study, we developed a novel recombinant HCA587 protein vaccine with Freund's adjuvants and $\mathrm{CpG}$ as adjuvant. The objective is to survey its ability inducing antigen specific immune response and antitumor activity in mice model.

\section{Methods}

The levels of cellular and humoral immune responses induced by different regimens were compared by IFN-y ELISpot and Ab ELISA, as well as by intracellular cytokine staining (ICS) analysis in different vaccination strategies. The tumor volume was measured and the survival curve was evaluated by logrank test.

\section{Results}

After the comparison of different strategies, HCA587 protein with CFA and 50 $\mu \mathrm{g}$ CpG elicited strongest specific IFN- $y$-secreting splenocytes and anti-HCA587 antibody. And this vaccine combination induced highest IFN- $\mathrm{\gamma}^{+} \mathrm{CD} 4^{+} \mathrm{T}$ cells by ICS analysis. When the B16-HCA587 tumor-bearing mice were inoculated with the HCA587 protein vaccine combined with CFA and CpG, the tumor growth was retarded significantly with no change of survival time.

\section{Conclusion}

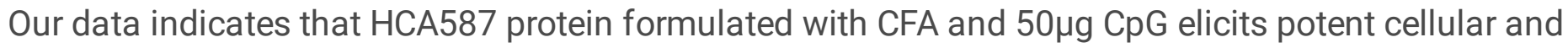
humoral immune responses and partial antitumor effect in mice model. This provides new experimental data for the preclinical research of HCA587 protein vaccine.

\section{Background}

In recent years, more and more attention has been paid to tumor immunotherapy. It has become a new trend of tumor immunotherapy to search for specific or related antigens expressed in tumor tissues, to prepare antigen-specific vaccines targeting tumors. Future perspectives of tumor vaccination are focused on more potent strategies of immunization [1].

Cancer-testis (CT) antigens which are expressed in several malignant tumors, but not in normal tissues except for testicular germ cells, are considered to be promising targets for specific CTL induced by peptide or protein vaccines. Many CT antigen vaccines exhibit strong and specific immune responses in 
mice models and can produce antitumor effect [2, 3]. HCA587 (also known as MAGE-C2), a hepatocellular carcinoma associated antigen, was cloned from the cDNA Expression Library of hepatocellular carcinoma (HCC) tissues by SEREX method in the early stage of the research [4]. In normal tissues, HCA587 protein was highly expressed only in immunoprivileged testis, and in many tumor tissues, such as liver cancer and melanoma [5]. In addition, spontaneous production of antibody against HCA587 could be detected in sera of tumor patients. In vitro, specific $\mathrm{CD} 8^{+} \mathrm{T}$ cell and $\mathrm{CD} 4^{+} \mathrm{T}$ cell responses could be induced by HCA587 recombinant protein from normal human peripheral blood [2]. These previous data indicate that HCA587 antigen has specific expression in tumor tissues and strong immunogenicity, which is a prerequisite for tumor vaccine candidate antigen.

Adjuvants enhance the immunogenicity of peptides and proteins by activating costimulatory factors and mediating the production of cytokines [1]. They induce early activation (although at different levels) of innate immunity which then translates into higher antibody and cellular responses to the vaccine antigens. In addition, most of these adjuvants clearly induce a wider breadth of adaptive responses able to confer protection against, for example, heterovariants of the viruses [6]. Immune adjuvant can reduce the amount of protein antigen under the condition of inducing the same intensity of response, and can improve the immunogenicity of protein antigen, enhance the specific humoral immune response and cellular immune response [7]. In recent years, adjuvants have been widely used in clinical trials of protein vaccines.

Therefore, it is of great significance to study the different immune strategies based on HCA587 protein and detect the immune responses induced by them. The aim of this study was to compare the cellular and humoral immune responses and antitumor effect of HCA587 protein under different immune strategies in a mouse model.

\section{Methods}

\subsection{Animals, cell lines}

C57BL/6 inbred mice $\left(\mathrm{H}-2^{\mathrm{b}}\right)$, purchased and fed at the Peking University Health Science Center, were used at 6-8 weeks. Animals were randomly distributed into seven groups of six animals each to receive HCA587 protein was combined with CFA/IFA and different doses of CpG adjuvant (20 $\mu \mathrm{g}$ or $50 \mu \mathrm{g})$ with adjuvants control and buffer control. All animals were given sterile drinking water and fed with standard laboratory food. Each mouse was observed daily for general health during the immunization scheme. All animal studies were complied by the Guide for the Care and Use of Laboratory Animals of the National Institutes of Health. The protocol was approved by the Second Affiliated Hospital of Nanchang University Medical Research Ethics Committee.

The B16 melanoma cell was transfected with plasmid pEGFP-C1 containing the full-length HCA587 cDNA sequence. Stable transfectants were selected in G418 and cloned by limiting dilution [8]. HCA587 expression of each clone was confirmed by Western blot method. 


\subsection{Proteins, adjuvants}

The construction of pGEX-6P-1-HCA587 recombinant plasmid and the expression and purification of HCA587 recombinant protein were finished by Crown Bioscience, Inc (Beijing, China) [8]. The purity of HCA587 protein was $>98 \%$. OVA protein (>95\% purity) was bought from Sigma-Aldrich (St. Louis, MO). Phosphorothioate modified CpG oligonucleotide (CpG ODN) 1826 (5' -TCCATGACGTTCCTGACGTT-3') was synthesized by the Shanghai Sangon Biological Engineering \& Technology and Service (Shanghai, China). Freund's complete adjuvants (CFA) and incomplete adjuvants (IFA) were obtained from Sigma.

\subsection{Immunization}

Groups of mice were immunized s.c. with $100 \mu$ l total volume at the base of the tail, twice, 3-week interval, with recombinant HCA587 protein given with adjuvants. $10 \mu \mathrm{g}$ HCA587 protein was prepared for immunization mixed 1:1 with CFA or IFA alone, or mixed with different doses of CpG ODN 1826 (20 $\mu$ g or $50 \mu \mathrm{g})$. As control, groups of age-matched mice were immunized with sterile PBS or the adjuvants CpG ODN 1826 with CFA or IFA.

\subsection{Therapeutic antitumor model in C57BL/6 mouse}

$1 \times 10^{4}$ B16-HCA587 tumor cells per mouse were injected s.c. into the flank. One week later, they were treated twice with s.c. injection of HCA587 protein which was combined with Freund's adjuvant (containing CFA or IFA) and different doses of $\mathrm{CpG}$ adjuvant (containing $20 \mu \mathrm{g}$ or $50 \mu \mathrm{g}$ ) with adjuvants control and buffer control at 3-week interval. Tumor volume was measured with a caliper every 2 to 3 days, and

calculated using the following formula: long axis $\times$ (short axis) ${ }^{2} \times 0.52$.

\subsection{Antibody ELISA assay}

Two weeks after the second immunization, sera were collected to detect antibody response to recombinant HCA587 protein by ELISA. Plates were coated with $1 \mu \mathrm{g} / \mathrm{ml} \mathrm{HCA587}$ protein and followed by blocked with PBS containing 2\% BSA. Then sera were added at certain dilutions for 2 hours incubation at $37^{\circ} \mathrm{C}$. The plates were incubated with horseradish peroxidase-conjugated anti-mouse IgG (Promega, Madison, $\mathrm{WI}$ ), with the corresponding substrate [8]. The reaction was stopped by the addition of $2 \mathrm{~mol} / \mathrm{L}$ $\mathrm{H}_{2} \mathrm{SO}_{4}$, and the absorbance was read at $450 \mathrm{~nm}$.

\subsection{IFN-y ELISpot assay}

Splenocytes were collected two weeks after the second immunization. Splenocytes $\left(5 \times 10^{5} /\right.$ well) were added to the 96-well plate precoated with anti-IFN- $y$ capture Abs, in the presence of different stimulators. The plate was incubated for 20 hours at $37^{\circ} \mathrm{C}$. After cells were removed, the plates were developed with a biotinylated anti-mouse IFN-y detecting Abs and streptavidin alkaline phosphatase [8]. The dark violet spots displayed on the plate membranes were automatically counted using a computer-assisted video image analyzer (Sage Creation, Beijing, China). 


\subsection{FACS analysis for intracellular cytokines}

For intracellular cytokine staining of T-cell population, $5 \times 10^{6} / \mathrm{ml}$ splenocytes were incubated at $37^{\circ} \mathrm{C}$ for 24 hours in RPMI-1640 (Invitrogen, Cralsbad, CA) and 10\% FCS (Invitrogen), 10 $\mathrm{gg} / \mathrm{ml} \mathrm{HCA587} \mathrm{protein,} \mathrm{as}$ OVA protein as control. Brefeldin A (10 $\mathrm{g} / \mathrm{ml}$; Biolegend, San Diego, CA) was added at the final 6 hours incubation. The cells were harvested, washed and stained for FITC-anti-CD4 and PerCP-anti-CD8 antibodies (BD, San Jose, $C A$ ) against surface marker. Then cells were washed once, and fixed with Fixation Buffer (Biolegend) for 20 minutes at room temperature, then washed again and permeabilized by incubation in 1× Permeabilization Buffer (Biolegend) for 10 minutes at room temperature. Permeabilized cells were stained with PE-anti-IFN-y, APC-anti-IL-4 and isotype-matched control IgG (Biolegend). After staining, the cells were washed twice with $1 \times$ Permeabilization Buffer, then resuspended in PBS buffer with $2 \%$ newborn calf serum (NCS) for FACS analysis (FACSCalibur; BD).

\subsection{Statistical analysis}

Statistical analysis of IFN-y production, antibody titer, and the comparison of tumor volume was performed using Student's $t$ test. The survival of mice was analyzed using the Kaplan-Meier method, and groups were compared using the log-rank test. Differences were considered to be significant when $P<$ 0.05 .

\section{Results}

\subsection{HCA587 protein combined with CFA and 50 $\mu \mathrm{gCpG}$ elicits strong cellular immune response}

To analyze the cell frequency of IFN-y secreted by HCA587 antigen-specific splenocytes induced by different immune strategies, ELISpot method was used and mice were immunized with HCA587 protein in combination with various adjuvants. The result showed that the high-intensity IFN-y secretion could be detected in the group of the combination of HCA587 with CFA and CpG, especially $50 \mu \mathrm{g}$ CpG strategy. The weak response could only be detected in the group of the combination of HCA587 with IFA and CpG, while no positive response could be detected in the group of the combination of HCA587 and IFA. The result indicates that HCA587 protein needs CFA and CpG to induce strong IFN- $\gamma$ secretion, and CpG at 50 $\mu \mathrm{g}$ is more potent than that at $20 \mu \mathrm{g}$ (Fig. 1).

\subsection{HCA587 protein combined with CFA and $50 \mu \mathrm{g}$ CpG stimulates strong humoral immune response}

ELISA method was used to detect the level of anti-HCA587 antibody induced by different immune strategies. Combined with previous results, high levels of HCA587-specific antibodies could be detected by combining HCA587 protein with CFA or IFA, which did not depend on the presence or dose of CpG (Fig. 2). Although there were no statistically significant differences in antibody titers between groups, HCA587 combined with CFA plus $50 \mu \mathrm{g}$ CpG generated the highest anti-HCA587 antibody titer at multiple dilutions. Overall, HCA587 combined with CFA plus $50 \mu \mathrm{g} \mathrm{CpG}$ is capable of inducing potent humoral immune response. 


\subsection{HCA587 protein combined with CFA and CpG induces HCA587-specific CD4 ${ }^{+} \mathrm{T}$ cells response}

Detection of the intracellular IFN- $\gamma$ in $\mathrm{CD}^{+} \mathrm{T}$ cells from several groups stimulated with HCA587 protein, the results showed that compared with the combination of HCA587 with IFA and CpG, the proportion of $\mathrm{CD} 4^{+} \mathrm{T}$ cells secreting IFN- $\gamma$ was higher in HCA587 combined with CFA and CpG, and the secreting ability of IFN- $\gamma$ at CpG $50 \mu \mathrm{g}$ was stronger than that at $20 \mu \mathrm{g}$ (Fig. 3). In contrast, no significant IFN- $\gamma$ secretion was observed in $\mathrm{CD}^{+} \mathrm{T}$ cells (data not shown). Again, IL-4-producing cell were not detected in either $\mathrm{CD} 4^{+}$or $\mathrm{CD} 8^{+}$populations.

\subsection{HCA587 protein combined with CFA and CpG produces antitumor effect in tumor model}

Based on the above results, we chose HCA587 protein combined with CFA and 50 $\mu \mathrm{g}$ CpG as the final vaccine strategy to observe antitumor effect. It did have specific antitumor effect in vivo and significantly delayed tumor growth (Fig. 4A), although the combination did not significantly improve survival in tumorbearing mice (Fig. 4B).

\section{Discussion}

The advantages of protein vaccine include many aspects, such as no $\mathrm{MHC}$ type restriction for human use, and inducing high-intensity integrated immune response containing $C D 4^{+} T, C D 8^{+} T$ cells and $B$ cells after uptake and presentation by professional antigen presenting cell(APC)in vivo [9]. In this study, we found that HCA587 combined with CFA plus $50 \mu \mathrm{g}$ CpG could induce potent cellular and humoral immune responses, and it did have specific antitumor effect in vivo and significantly delayed tumor growth.

It is important to understand the mechanism of action of adjuvants in order to establish an ideal immune response using existing and new adjuvants. The use of adjuvant at priming may presumably program the immune response to generate a stronger innate transcriptional response at enhancement, which can increase / enhance the adaptive immune response $[10,11]$. A vaccine adjuvant is a necessary condition to activate dendritic cells (DCs) and inducing a favorable immunologic milieu [12]. Freund's adjuvant reagent is a classic adjuvant, which divides into the complete Freund's adjuvant(CFA) and incomplete Freund's adjuvant (IFA). We have learned that they were widely used in protein vaccines to enhance the body's robust host immune response $[12,13]$. Therefore, HCA587 protein combined with CFA/IFA could induce strong humoral immune response with or without the presence of $\mathrm{CpG}$.

But some clinical researches report that Freund's adjuvant reagent need to be associated with other adjuvants to enhance its activity, such as toll-like receptor (TLR) 3 agonist and TLR4 agonist [14, 15], and CpG ODN and so on [16]. The research of Marit M. Melssen et al indicated that LPS and polyiclc combined with IFA are safe and effective vaccine adjuvants. When added to TLR agonists, IFA enhanced the response of T cells to peptide vaccines [14]. The research of Daniel E. Speiser et al indicated that vaccination with peptide, IFA and CpG ODN 7909 could lead rapid and strong human CD $8^{+} \mathrm{T}$ cell responses [16]. Moreover, previous reports showed that immunization with peptides in an emulsion with 
Montanide ISA 51 adjuvant (water-in-oil emulsion) might induce a Th2-dominant microenvironment, which suggested that the vaccine site microenvironment was not fully utilized for induction of strong Th1/Tc1 responses, with induction instead of FoxP ${ }^{+}$cells and eosinophils. It suggests that there is a Th2 dominant microenvironment [17]. The above supports our conclusion that Freund's adjuvant need other adjuvant to help inducing enough cellular immune response.

CpG oligodeoxynucleotides, which are TLR 9 ligands, are being widely tested as a potent adjuvant for peptide- and protein-based cancer vaccines that stimulate cancer-reactive CTLs [18]. CpG is a synthetic oligodeoxynucleotides containing $\mathrm{CpG}$ motifs, which is a potent driver of $\mathrm{B}$ cells and Th1 immune responses, and promotes the production of IFN-y secreting cytotoxic cells by cross-presentation $[16,19$, 20]. The cornerstone of vaccine effectiveness is whether the host immune response against an antigen can cause a memory $T$ cell response over time [21]. CpG adjuvant can induce strong immune response in vaccination trials. The research of $P$. Baumgaertner et al indicated that vaccination with the long synthetic NY-ESO-1 peptide combined with the strong immune adjuvant CpG-B induced integrated, robust and functional $\mathrm{CD}^{+}$and $\mathrm{CD} 4^{+}$T-cell responses and a significant enhancement of tumor-specific antibodies in melanoma patients $[22,23]$. Type I cytokines such as IFN- $\gamma$ secreted by $T$ cells play an important role in $T$ cell-mediated antitumor mechanism [24]. In the experiment, several immune strategies were compared by IFN-y ELISpot and Ab ELISA. HCA587 protein was combined with CFA/IFA and CpG. The results showed that HCA587 protein induced a large amount of IFN-y-producing splenocytes when combined with CFA and $\mathrm{CpG} 50 \mu \mathrm{g}$. At the same time, in order to understand the type of immune response after vaccination and the ability of immune cells to secrete cytokines, we also carried out intracellular cytokine staining. $\mathrm{CD}^{+} \mathrm{T}$ cells were the main group of IFN-y-secreting splenocytes induced by HCA587 and $50 \mu \mathrm{g} \mathrm{CpG}$. This indicates that HCA587 protein vaccine can induce specific Th1 type cellular immune response in mice, and the presence of $\mathrm{CpG}$ is vital for the elicitation of Th1 type cellular immune response.

In order to evaluate the antitumor effect of HCA587 protein vaccine in vivo, we constructed the HCA587positve B16 melanoma cells to inoculate C57BL/ 6 mice. HCA587 protein combined with CFA and $50 \mu \mathrm{g}$ CpG could specifically retard HCA587 antigen-positive tumor cells in mice, but it could not prolong the survival time of tumor-bearing mice. The reason for this may be related to the complexity of tumor microenvironment. PD-1/PD-L1 signaling pathway can inhibit T cell immune response and promote tumor immune escape [25]. The equilibrium state maintained by adaptive immunity is destroyed [26]. It is also possible that regulatory $\mathrm{T}$ (Treg) cells inhibit $\mathrm{T}$ cell response and function through a variety of direct and indirect mechanisms in tumor microenvironment [27]. In addition, we have learned that antigenspecific $\mathrm{CD} 8^{+} \mathrm{T}$ cells induced with IFA are disordered in their cytokine production and proliferative capability, and this may be a vital mechanism for the transient immune response and the low clinical response rate in Freund's adjuvant [12]. It also reported that the adjuvant fosters the recruitment, exhaustion and eventual death of T cells within the vaccination site [28]. Therefore we consider the possibility of better combinations of adjuvants, such as using the adjuvant combination of CpG and ISCOM $[8,29]$. It can also be treated with the combined checkpoint inhibitor PD-1 antibody. PCSK9 can also be inhibited so as to avoid the degradation of tumor cells such as MHC-1 [30]. 


\section{Conclusion}

In conclusion, we find that HCA587 protein combined with CFA and CpG adjuvants can induce potent cellular and humoral immune responses and have partial antitumor effects in mice model. This suggests that HCA587 protein vaccine need more proper strategies if there is a plan for it to enter the clinical trial in the future.

\section{Abbreviations}

CT

Cancer-testis

CFA

complete Freund's adjuvant

IFA

incomplete Freund's adjuvant

ICS

intracellular cytokine staining

ELISA

Enzyme-linked immunosorbent assay

CTL

Cytotoxic T lymphocytes

cDNA

Complementary DNA

$\mathrm{HCC}$

Hepatocellular carcinoma

SEREX

Serological analysis of recombinant cDNA expression libraries CpG ODN CpG oligodeoxynucleotides

$A b$

Antibody

APC

Antigen presenting cells

BSA

Bovine serum albumin

DCs

dendritic cells

TLR Toll-like family of receptors

Th

Helper T cells 
NY-ESO-1

New York esophageal squamous cancer-1

Tregs

Regulatory T lymphocytes

LPS

lipopolysaccharide

PD-1/PD-L1

programmed death 1(PD-1)and its ligand PD-L1

$\mathrm{MHC}$

Major histocompatibility complex.

\section{Declarations}

\section{Acknowledgements}

We are thankful for all the participants of this study.

\section{Authors' contributions}

JC and YY conceived and designed this study. WJ and HC performed the experiments. LZ and WY analyzed and interpreted the data. $\mathrm{HC}$ and JC wrote the manuscript. All authors reviewed and approved the final manuscript.

\section{Funding}

This work was supported by the National Natural Science Foundation of China (grant no. 81960497), Jiangxi Government Foundation for Youth Natural Sciences (grant nos. 20181BAB215026 and 20192BAB215016), Jiangxi Provincial Department of Education (grant no. GJJ170154), Health Commission of Jiangxi Province, P.R. China (grant no. 20201061).

\section{Availability of data and materials}

All data generated or analyzed during this study are included in this article in Figs. 1, 2, 3 and 4 . There was no public dataset used in our study. The original experiment data of the current study are not publicly available but are available from the corresponding author on reasonable request.

\section{Ethics approval and consent to participate}

Experiments with animals were carried out in compliance with the ARRIVE guidelines and all methods were carried out in accordance with relevant guidelines and regulations. The protocol was approved by the Second Affiliated Hospital of Nanchang University Medical Research Ethics Committee (Permit Number: 2015.056). All efforts were made to minimize suffering. When the animal suffering was too great, humane endpoints were applied. Mice were sacrificed using cervical dislocation after 
intraperitoneal injection of $50 \mathrm{mg} / \mathrm{kg}$ sodium pentobarbitone according to Chinese Guidelines for the Euthanasia of Laboratory Animals.

\section{Consent for publication}

Not applicable.

\section{Competing interests}

The authors declare that they have no competing interests.

\section{Author details}

1 Jiangxi Province Key Laboratory of Laboratory Medicine, Department of Clinical Laboratory, the Second Affiliated Hospital of Nanchang University, Nanchang 330006, Jiangxi, China. ${ }^{2}$ Department of Immunology, School of Basic Medical Sciences, and Key Laboratory of Medical Immunology of Ministry of Health, Peking University Health Science Center, Beijing 100191, China. ${ }^{3}$ Hematological Research Institute, Shaanxi Provincial People's Hospital, Xi'an 710068, Shaanxi, China.

\section{References}

1. Jäger E, Jäger D, Knuth A. Peptide Vaccination in Clinical Oncology. Onkologie 2000, 23(5):410-5. https://doi.org/10.1159/000027202.

2. Li B, He X, Pang X, Zhang H, Chen J, Chen W. Elicitation of both CD4 and CD8 T-cell-mediated specific immune responses to HCA587 protein by autologous dendritic cells. Scand J Immunol 2004, 60(5):506-13. https://doi.org/10.1111/j.0300-9475.2004.01503.x.

3. Giavina-Bianchi MH, Giavina-Bianchi PFJ, Festa CN. Melanoma: tumor microenvironment and new treatments. An Bras Dermatol 2017,92(2):156-66. https://doi.org/10.1590/ abd1806-4841.20176183.

4. Wang Y, Han KJ, Pang XW, Vaughan HA, Qu W, Dong XY, Peng JR, Zhao HT, Rui JA, Leng XS et al. Large scale identification of human hepatocellular carcinoma-associated antigens by autoantibodies. J Immunol 2002, 169(2):1102-9. https://doi.org/10.4049/jimmunol.169.2. 1102.

5. Li B, Qian XP, Pang XW, Zou WZ, Wang YP, Wu HY, Chen WF. HCA587 antigen expression in normal tissues and cancers: correlation with tumor differentiation in hepatocellular carcinoma. Lab Invest 2003,83(8):1185-92. https://doi.org/10.1097/01.lab.0000080605. 73839.96.

6. Del Giudice G, Rappuoli R, Didierlaurent AM. Correlates of adjuvanticity. A review on adjuvants in licensed vaccines. Semin Immunol 2018,39:14-21. https://doi.org/10.1016/ j.smim.2018.05.001.

7. Stewart-Tull DE. Adjuvant formulations for experimental vaccines. Methods in molecular medicine 2003, 87:175-94. https://doi.org/10.1385/1-59259-399-2:175.

8. Chen J, Zhang L, Wen W, Hao J, Zeng P, Qian X, Zhang Y, Yin Y. Induction of HCA587-specific antitumor immunity with HCA587 protein formulated with CpG and ISCOM in mice. PLoS One 2012, 7(10):e47219. https://doi.org/10.1371/journal. pone.0047219. 
9. Atanackovic D, Altorki NK, Cao Y, Ritter E, Ferrara CA, Ritter G, Hoffman EW, Bokemeyer C, Old LJ, Gnjatic S. Booster vaccination of cancer patients with MAGE-A3 protein reveals long-term immunological memory or tolerance depending on priming. Proceedings of the National Academy of Sciences of the United States of America 2008, 105(5):1650-5.

https://doi.org/10.1073/pnas.0707140104.

10. Pedersen GK, Andersen P, Christensen D. Immunocorrelates of CAF family adjuvants. Semin Immunol 2018, 39:4-13. https://doi.org/10.1016/j.smim.2018.10.003.

11. Harandi AM. Systems analysis of human vaccine adjuvants. Semin Immunol 2018, 39:30-4. https://doi.org/10.1016/j.smim.2018.08.001.

12. Salerno EP, Shea SM, Olson WC, Petroni GR, Smolkin ME, McSkimming C, Chianese-Bullock KA, Slingluff CL, Jr. Activation, dysfunction and retention of T cells in vaccine sites after injection of incomplete Freund's adjuvant, with or without peptide. Cancer Immunol Immunother 2013, 62(7):1149-59. https://doi.org/10.1007/s00262-013-1435-5.

13. Wang Z, Jiang J, Li Z, Zhang J, Wang H, Qin Z. A myeloid cell population induced by Freund adjuvant suppresses T-cell-mediated antitumor immunity. J Immunother 2010, 33(2):167-77. https://doi.org/10.1097/CJI.0b013e3181bed2ba.

14. Melssen MM, Petroni GR, Chianese-Bullock KA, Wages NA, Grosh WW, Varhegyi N, Smolkin ME, Smith KT, Galeassi NV, Deacon DH et al. A multipeptide vaccine plus toll-like receptor agonists LPS or polyICLC in combination with incomplete Freund's adjuvant in melanoma patients. J Immunother Cancer 2019, 7(1):163. https://doi.org/10.1186/s40425- 019-0625-X.

15. Melssen MM, Pollack KE, Meneveau MO, Smolkin ME, Pinczewski J, Koeppel AF, Turner SD, SolChurch K, Hickman A, Deacon DH et al. Characterization and comparison of innate and adaptive immune responses at vaccine sites in melanoma vaccine clinical trials. Cancer Immunol Immunother 2021,70(8):2151-64. https://doi.org/10.1007/s00262-020-02844- w.

16. Speiser DE, Liénard D, Rufer N, Rubio-Godoy V, Rimoldi D, Lejeune F, Krieg AM, Cerottini JC, Romero P. Rapid and strong human CD8+ T cell responses to vaccination with peptide, IFA, and CpG oligodeoxynucleotide 7909. J Clin Invest 2005, 115(3):739-46. https://doi.org/10.1172/jci23373.

17. Schaefer JT, Patterson JW, Deacon DH, Smolkin ME, Petroni GR, Jackson EM, Slingluff CL, Jr. Dynamic changes in cellular infiltrates with repeated cutaneous vaccination: a histologic and immunophenotypic analysis. J Transl Med 2010, 8:79. https://doi.org/10.1186/ 1479-5876-8-79.

18. Kawahara $M$, Takaku $\mathrm{H}$. A tumor lysate is an effective vaccine antigen for the stimulation of CD4(+) T-cell function and subsequent induction of antitumor immunity mediated by CD8(+) T cells. Cancer Biol Ther 2015,16(11):1616-25. https://doi.org/10.1080/15384047. 2015.1078027.

19. Romagnani S. Human $\mathrm{TH} 1$ and $\mathrm{TH} 2$ subsets: regulation of differentiation and role in protection and immunopathology. Int Arch Allergy Immunol 1992, 98(4):279-85. https://doi.org/10.1159/000236199.

20. Krieg AM, Yi AK, Matson S, Waldschmidt TJ, Bishop GA, Teasdale R, Koretzky GA, Klinman DM. CpG motifs in bacterial DNA trigger direct B-cell activation. Nature 1995, 374(6522):546-9. 
https://doi.org/10.1038/374546a0.

21. Guimarães LE, Baker B, Perricone $C$, Shoenfeld Y. Vaccines, adjuvants and autoimmunity. Pharmacol Res 2015, 100:190-209. https://doi.org/10.1016/j.phrs.2015.08.003.

22. Baumgaertner P, Costa Nunes C, Cachot A, Maby-El Hajjami H, Cagnon L, Braun M, Derré L, Rivals JP, Rimoldi D, Gnjatic $S$ et al. Vaccination of stage III/IV melanoma patients with long NY-ESO-1 peptide and CpG-B elicits robust CD8(+) and CD4(+) T-cell responses with multiple specificities including a novel DR7-restricted epitope. Oncoimmunology 2016, 5(10):e1216290.

https://doi.org/10.1080/2162402x.2016.1216290.

23. Valmori D, Souleimanian NE, Tosello V, Bhardwaj N, Adams S, O'Neill D, Pavlick A, Escalon JB, Cruz $\mathrm{CM}$, Angiulli A et al. Vaccination with NY-ESO-1 protein and $\mathrm{CpG}$ in Montanide induces integrated antibody/Th1 responses and CD8 T cells through cross-priming. Proc Natl Acad Sci U S A 2007, 104(21):8947-52. https://doi.org/10.1073/pnas.0703395104.

24. Romagnani S. Human $\mathrm{TH} 1$ and $\mathrm{TH} 2$ subsets: regulation of differentiation and role in protection and immunopathology. International archives of allergy and immunology 1992, 98(4):279-85. https://doi.org/10.1159/000236199.

25. Zhu X, Lang J. Soluble PD-1 and PD-L1: predictive and prognostic significance in cancer. Oncotarget 2017, 8(57):97671-82. https://doi.org/10.18632/oncotarget.18311.

26. Koebel CM, Vermi W, Swann JB, Zerafa N, Rodig SJ, Old LJ, Smyth MJ, Schreiber RD. Adaptive immunity maintains occult cancer in an equilibrium state. Nature 2007, 450(7171):903-7. https://doi.org/10.1038/nature06309.

27. Sakaguchi S, Sakaguchi N, Asano M, Itoh M, Toda M. Immunologic self-tolerance maintained by activated T cells expressing IL-2 receptor alpha-chains (CD25). Breakdown of a single mechanism of self-tolerance causes various autoimmune diseases. J Immunol 1995, 155(3):1151-64. https://doi.org/10.1177/1753425910361989.

28. Hailemichael Y, Dai Z, Jaffarzad N, Ye Y, Medina MA, Huang XF, Dorta-Estremera SM, Greeley NR, Nitti $\mathrm{G}$, Peng $\mathrm{W}$ et al. Persistent antigen at vaccination sites induces tumor-specific CD8 T cell sequestration, dysfunction and deletion. Nat Med 2013, 19(4):465-72. https://doi.org/10.1038/nm.3105.

29. Harland DN, Chu K, Haque A, Nelson M, Walker NJ, Sarkar-Tyson M, Atkins TP, Moore B, Brown KA, Bancroft $\mathrm{G}$ et al. Identification of a LolC homologue in Burkholderia pseudomallei, a novel protective antigen for melioidosis. Infect Immun 2007, 75(8):4173-80. https://doi.org/10.1128/iai.00404-07.

30. Liu X, Bao X, Hu M, Chang H, Jiao M, Cheng J, Xie L, Huang Q, Li F, Li C-Y. Inhibition of PCSK9 potentiates immune checkpoint therapy for cancer. Nature 2020, 588(7839):693-8. https://doi.org10.1038/s41586-020-2911-7.

\section{Figures}




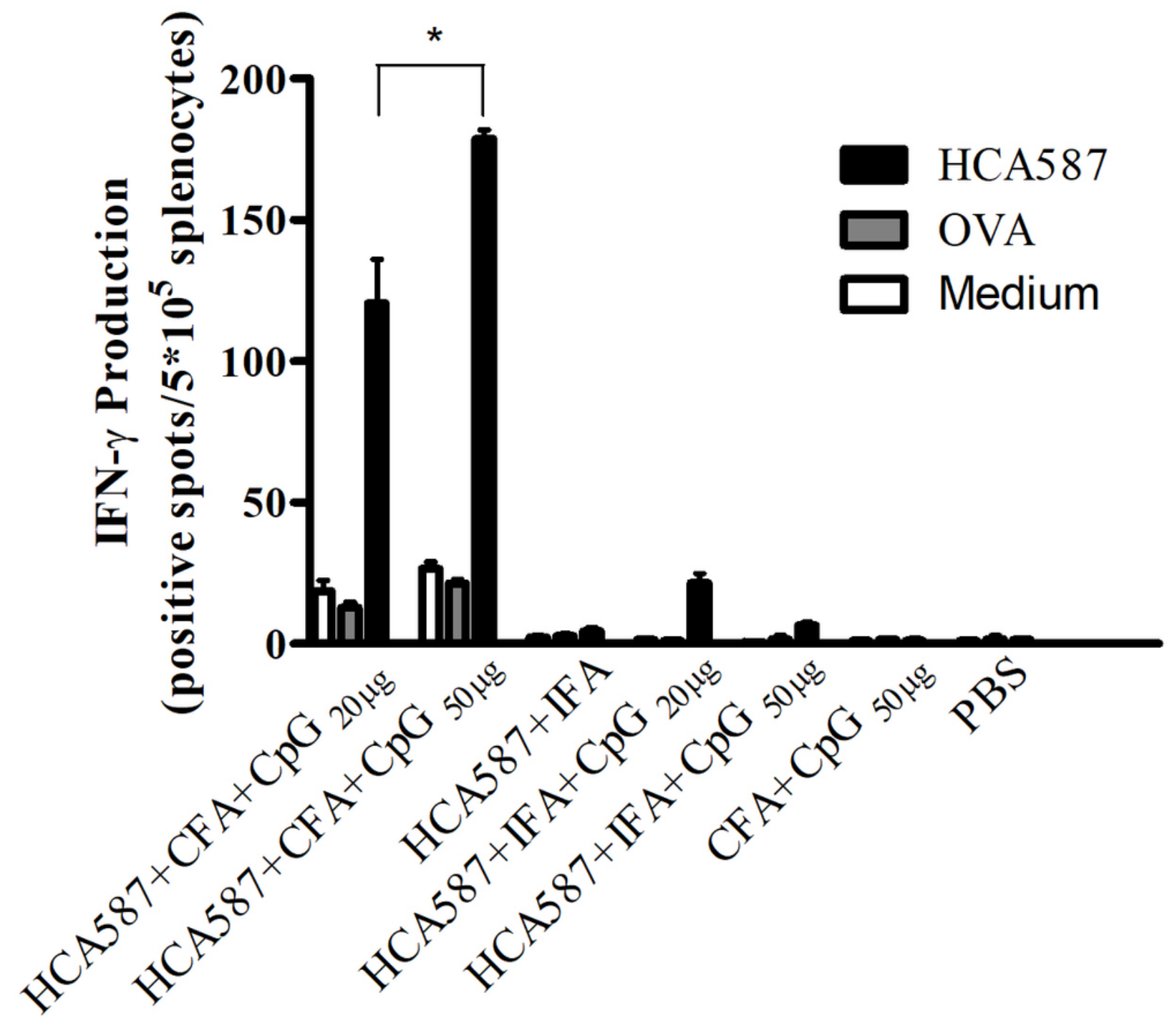

Figure 1

Effective cellular immunity induced by different vaccine strategies. HCA587 protein was combined with CFA/IFA and different doses of CpG adjuvant (20mg or $50 \mathrm{mg}$ ) with adjuvants control and buffer control.

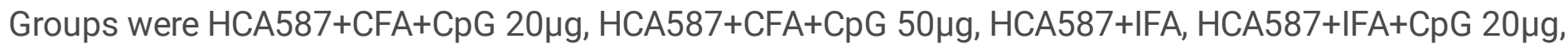
HCA587+IFA+CpG 50 $\mu \mathrm{g}, \mathrm{CFA}+\mathrm{CpG} 50 \mu \mathrm{g}$ as adjuvants control, PBS buffer control. *, $\mathrm{P}<0.05$,

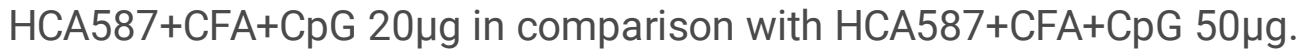




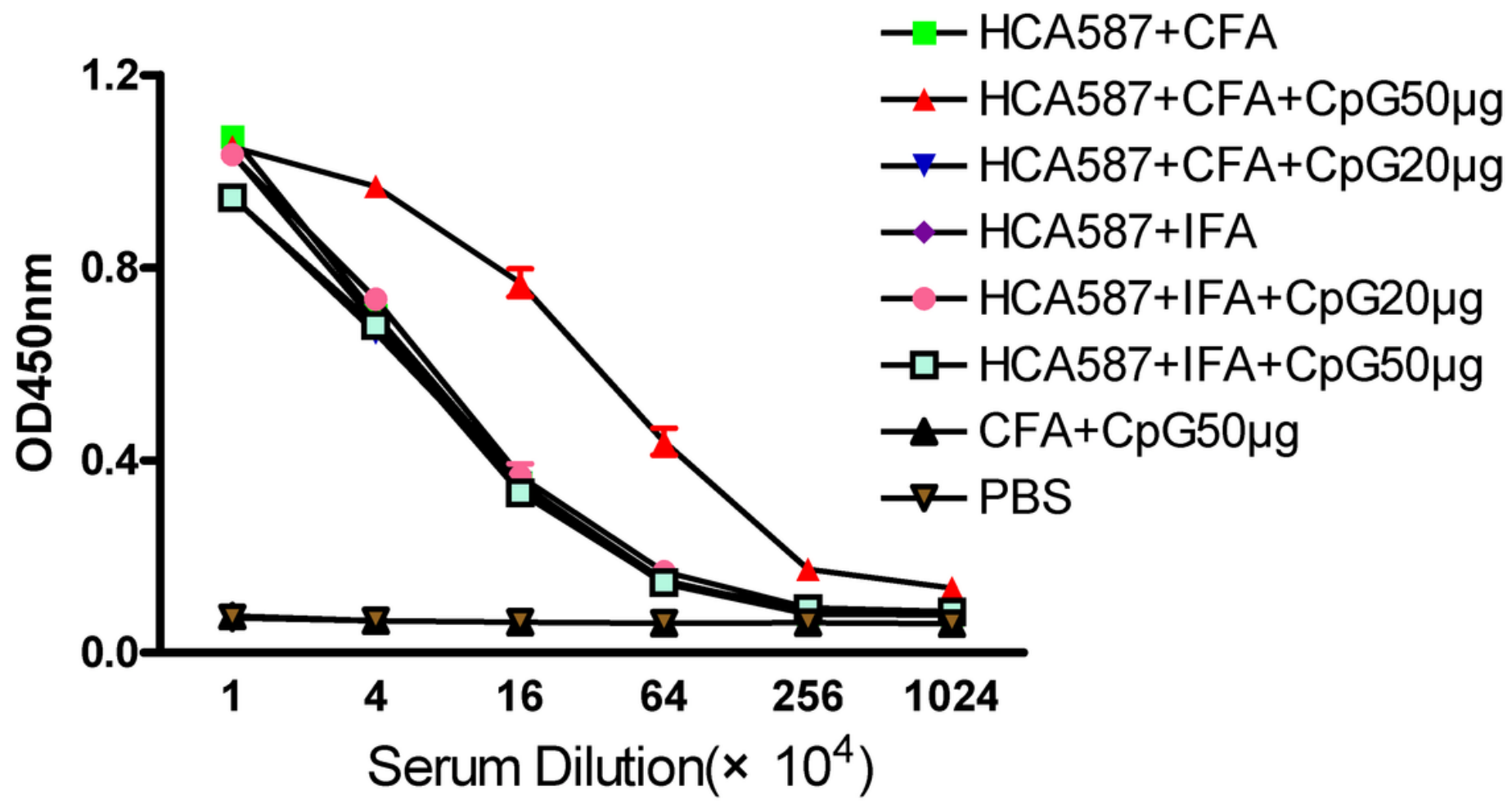

Figure 2

The detection of anti-HCA587 total IgG antibody.

C57BL/6 mice were respectively immunized with group as shown in Figure 1 at 3-week interval. Two weeks after the second immunization, sera were harvested. Serum samples in each group were pooled to detect anti-HCA587 antibody titer by ELISA. 
B

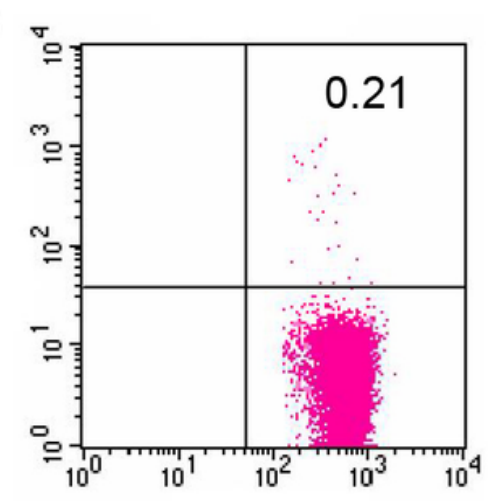

$\mathbf{E}$
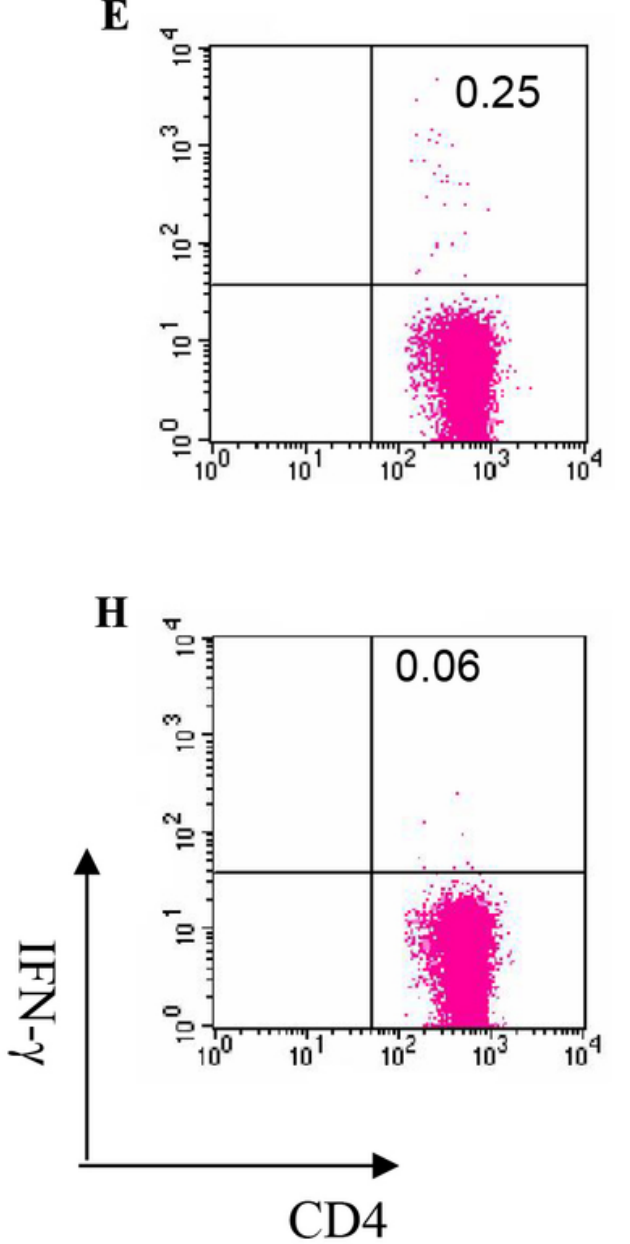

C

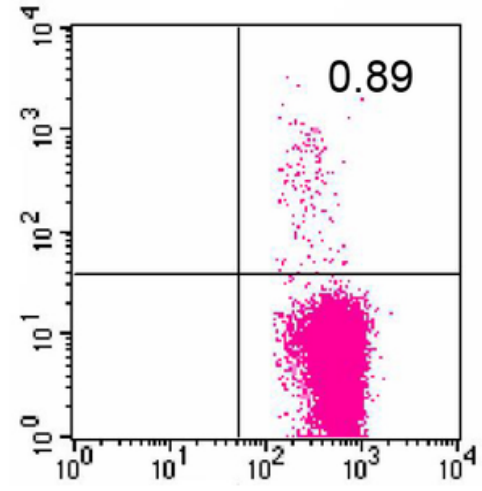

$\mathbf{F}$

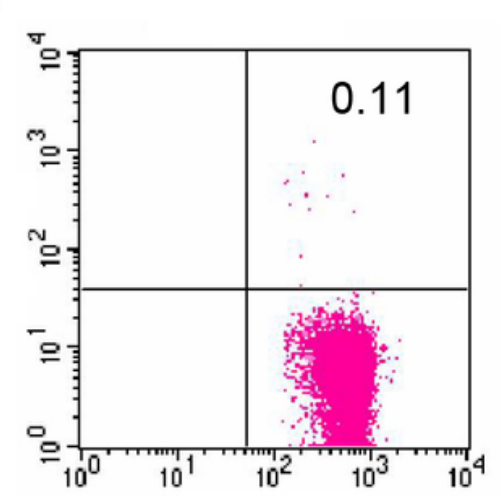

I

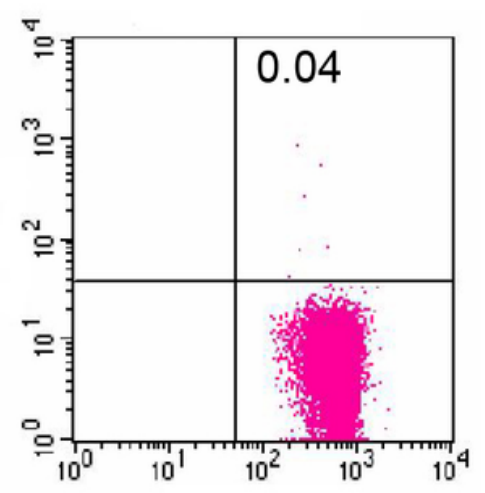

D

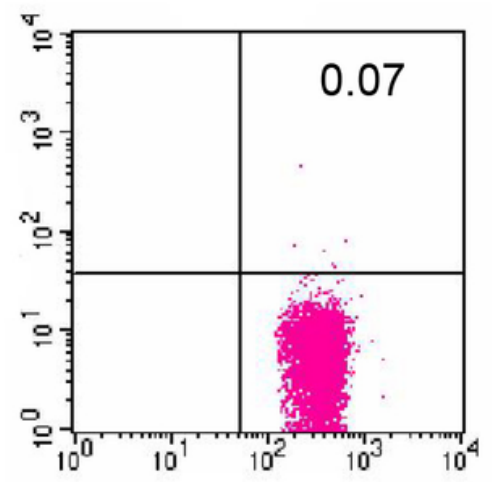

G

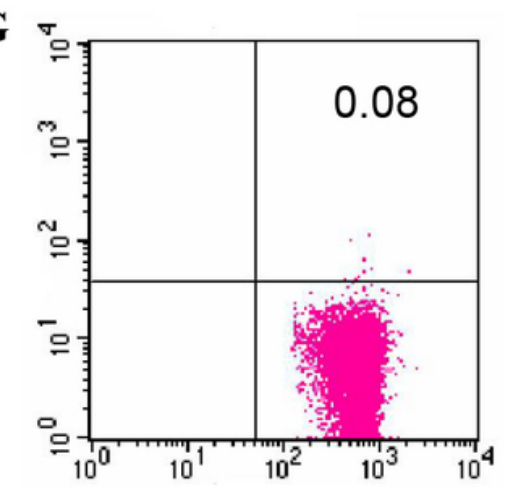

$\mathbf{J}$

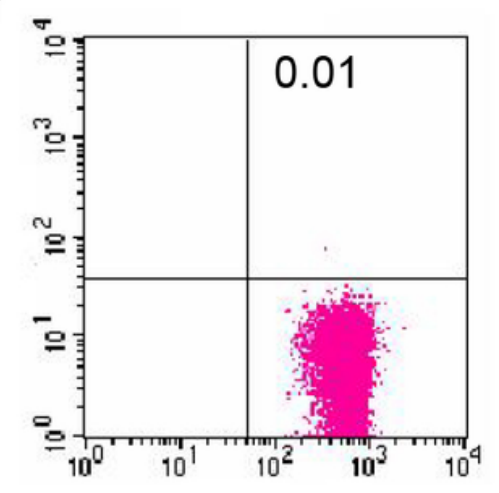

Figure 3

IFN-y secreted by CD4+ T cells from stimulated splenocytes following vaccination with HCA587 protein plus CFA/IFA and CpG.

Mice were immunized with different vaccine strategies. After the second immunization, splenocytes were harvested and stimulated with OVA protein, or HCA587 protein for 24 hours culture. For intracellular IFN- $\gamma$ staining under HCA587 protein stimulation, CD4+ T cells of splenocytes were detected (A, 


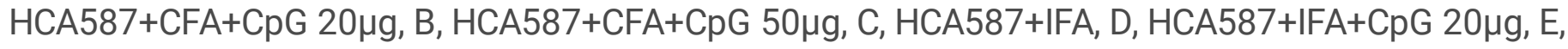

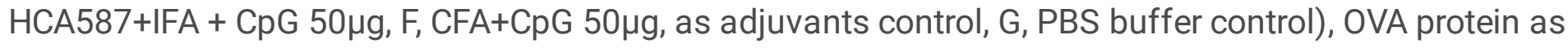
protein control (Fig. $3 \mathrm{H}$ ), and IgG antibody control as isotype control (Fig. 3I).
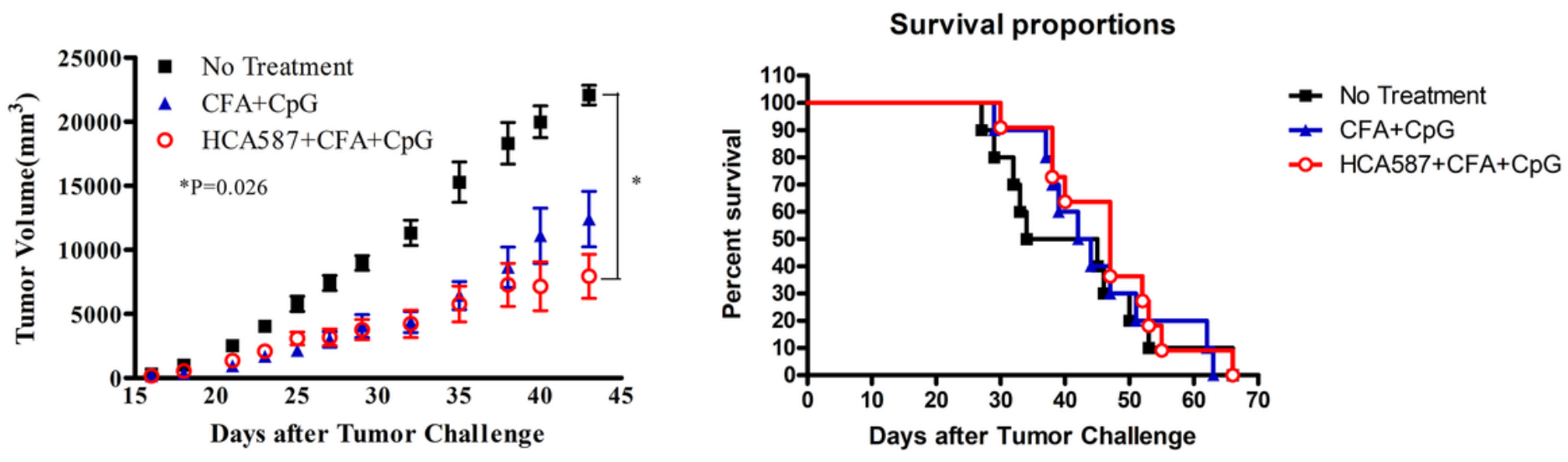

Figure 4

Inhibition of tumor growth, but failure to prolong the survival of B16-HCA587 tumor-bearing mice following treatment with HCA587 protein with CFA and $50 \mu \mathrm{g}$ CpG.

C57BL/ 6 mice ( $n=10-11 /$ group) were inoculated with 1×104/mouse B16-HCA587 tumor cells s. c. into the flank on day 0 . On days 7 and 28, mice were treated at the tail with HCA587 protein formulated with

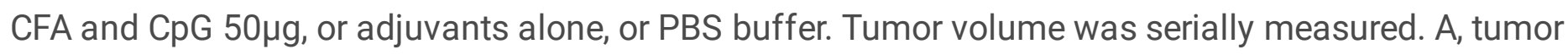
growth. ${ }^{*} \mathrm{P}=0.026$ for the comparison of HCA587+CFA+CpG group and untreated group. $B$, survival of tumor-bearing mice. Overall survival proportion of mice treated above was shown. Statistical analysis was performed using log-rank test. 